\section{Färbung, Urin}

W. G. Guder

München, Deutschland

Synonym(e) Harnfarbe-Beurteilung; Uroskopie

Englischer Begriff urine colour

Definition Die Färbung des Urins stellt eine wesentliche Komponente der Analyse des Urins mit diagnostischen Zielen dar („Uroskopie“). Es beschreibt die visuell sichtbare Färbung des Urins, vgl. dazu folgende Tabelle:

\begin{tabular}{|c|c|c|}
\hline Aussehen & Ursachen & Symptom bei \\
\hline Blass, wässrig & Verdünnter Urin & $\begin{array}{l}\text { Polyurie, Diabetes } \\
\text { insipidus, Diabetes } \\
\text { mellitus, } \\
\text { Hypostenurie }\end{array}$ \\
\hline Bernsteingelb & $\begin{array}{l}\text { Gallenfarbstoffe, } \\
\text { Nahrungsfarbstoffe } \\
\text { (z. B. Flavine) }\end{array}$ & $\begin{array}{l}\text { Normaler Urin, } \\
\text { Vitamin } \mathrm{B}_{2}, \\
\text { Einnahme von } \\
\text { Medikamenten }\end{array}$ \\
\hline Gelborange & $\begin{array}{l}\text { Gallenfarbstoffe, } \\
\text { Nahrungsfarbstoffe } \\
\text { (z. B. Rhabarber, Folia } \\
\text { Sennae) }\end{array}$ & $\begin{array}{l}\text { Konzentrierter Urin, } \\
\text { Cholestase }\end{array}$ \\
\hline $\begin{array}{l}\text { Bräunlich- } \\
\text { (,,bier“)braun }\end{array}$ & Biliverdin, Bilirubin & Hepatischer Ikterus \\
\hline $\begin{array}{l}\text { Rötlich- } \\
\text { rötlichbraun }\end{array}$ & $\begin{array}{l}\text { Hämoglobin(derivate), } \\
\text { Myoglobin, } \\
\text { Porphyrine, } \\
\text { Medikamente (z. B. } \\
\text { L-Dopa, Metronidazol, } \\
\text { Chinin, Phenacetin, } \\
\text { Rote-Bete-Konsum) }\end{array}$ & $\begin{array}{l}\text { Hämaturie, } \\
\text { Hämoglobinurie, } \\
\text { Rhabdomyolyse, } \\
\text { Therapeutika }\end{array}$ \\
\hline $\begin{array}{l}\text { Gelbgrün, } \\
\text { blaugrün }\end{array}$ & $\begin{array}{l}\text { Gallenfarbstoffe im } \\
\text { alkalischen Urin, }\end{array}$ & $\begin{array}{l}\text { Cholestase, } \\
\text { Farbstoffe, }\end{array}$ \\
\hline
\end{tabular}

(Fortsetzung)

\begin{tabular}{|c|c|c|}
\hline Aussehen & Ursachen & Symptom bei \\
\hline & $\begin{array}{l}\text { Indikane, Polycyanin, } \\
\text { Chlorophyll }\end{array}$ & $\begin{array}{l}\text { Pseudomonas- } \\
\text { Infektion, } \\
\text { Mundspülmittel }\end{array}$ \\
\hline $\begin{array}{l}\text { Dunkelbraun- } \\
\text { schwarz, evtl. } \\
\text { beim Stehen } \\
\text { dunkelnd }\end{array}$ & $\begin{array}{l}\text { Methämoglobin, } \\
\text { Homogentisinsäure, } \\
\text { Melanin, Porphyrine, } \\
\text { Serotonin, } \\
\text { Medikamente }\end{array}$ & $\begin{array}{l}\text { Hämolyse, } \\
\text { Alkaptonurie, } \\
\text { Melanom, } \\
\text { „Melanose“, } \\
\text { Chlorpromazin, } \\
\text { Methyl-Dopa }\end{array}$ \\
\hline $\begin{array}{l}\text { Weiß, milchig- } \\
\text { trüb oder wolkig }\end{array}$ & $\begin{array}{l}\text { Eiter, Schleim, Lipide, } \\
\text { Chylus, Paraffin, } \\
\text { Bakterien, } \\
\text { Kontrastmittel }\end{array}$ & $\begin{array}{l}\text { Infektion der } \\
\text { ableitenden } \\
\text { Harnwege, } \\
\text { Chylusfistel, } \\
\text { Vaginalcreme }\end{array}$ \\
\hline Trüb-blau & Indikan, Medikamente & $\begin{array}{l}\text { Systemische Infektion } \\
\text { (Typhus, Sepsis) }\end{array}$ \\
\hline
\end{tabular}

Beschreibung Die Farbe des Urins stellt nicht nur für den Laien, sondern auch für den Arzt seit der Antike ein mit dem Auge sichtbares Zeichen zur Beurteilung des Gesundheitsstands dar. War die Betrachtung des Urins durch die Uroskopie im Mittelalter charakterisiert durch die Differenzierung von 20 verschiedenen Farben, die im Zusammenhang mit der 4-Säfte-Lehre der Antike interpretiert wurden, ist die Harnfarbe seit dem 19. Jahrhundert, als man die Ursachen der meisten Harnfarben identifizierte, Basis für die Diagnose/das Symptom, da zahlreiche Symptome/Erkrankungen nach der Harnfarbe benannt wurden: Hämaturie, Porphyrie, Alkaptonurie, Melanurie, Schwarzwasserfieber.

\section{Literatur}

Hofmann W, Ehrich JHH, Guder WG, Keller F, Scherberich J (2011) Diagnostische Pfade bei Nierenerkrankungen. J Lab Med 35:127-146

Vosswinckel P (1993) Der Schwarze Urin. Blackwell Wissenschaft, Berlin 